\title{
0 LETRADO NO SETECENTOS MINEIRO: A FORMAÇÃO DO POETA
}

Reinaldo Martiniano Marques

$U F M G$

\begin{abstract}
RESUMO:
A partir da perspectiva de uma análise arqueológica do discurso poético do Setecentos mineiro, tendo como corpus a poesia de Cláudio Manuel da Costa e Tomás Antônio Gonzaga, este artigo analisa o agente de sua enunciação, evidenciando o percurso da formação do letrado e seus atributos - as práticas da escrita e da leitura -, formação e predicados que o habilitam a enunciar um discurso poético legitimado. PALAVRAS CHAVE:
\end{abstract}

Literatura Brasileira, Poesia Colonial, Poeta.

A partir da perspectiva de uma análise arqueológica do discurso poético do Setecentos mineiro, procurarei considerar, neste artigo, um aspecto da sua instância de enunciação: o seu agente, ou sujeito. Ao se pensar a instância de enunciação do discurso poético, na Vila Rica da segunda metade do século XVIII, importa responder a uma questão primeira e fundamental: Quem profere esse discurso? Que indivíduos, dotados de certos predicados, aí estão capacitados a enunciar discursos? Inserido o discurso poético numa cadeia de comunicação, como mensagem esteticamente codificada, num primeiro momento trata-se de caracterizar o seu emissor. Em outros termos, o agente da enunciação. E por agente, entenda-se o termo aqui num sentido mais filosofico: o princípio ou 
sujeito de uma ação. Remete o agente à sede física, psicológica, social ou moral da ação. No caso do discurso poético do Setecentos mineiro, não está em jogo nenhum princípio mítico ou mágico. $O$ agente de sua enunciação designa 0 letrado com seus atributos: as práticas da escrita e da leitura.

Carece de ter presente também a lição foucaultiana,' anteriormente apontada, de que o nome do autor não remete a um indivíduo exterior ao discurso e que o produz, reduzindo-se a ele. Trata-se, antes, de uma função autoral, que cumpre determinado papel no processo de produção, circulação e funcionamento dos discursos na sociedade. Não há, portanto, uma simetria e continuidade entre o nome do autor e o escritor real, indivíduo histórico situado no tempo e no espaço. Ademais, uma vez que a função autoral não se desenvolve espontaneamente mas consiste numa operação complexa de construção do "autor", ela varia de uma época para outra. Assim, a construção do "poeta" no Setecentos haverá de ser diferente da que ocorre posteriormente, nos séculos XIX e XX.

Por outro lado, não se pode desconhecer a dimensão histórica das formações discursivas, de suas regras de formação, que supõem condições materiais e culturais de existência e coexistência, de permanência e mudança dos discursos. ${ }^{2}$ Com isso, ao se tentar definir o agente de enunciação do discurso poético em Vila Rica, faz-se mister considerar o escritor real, ou seja, aquele indivíduo histórico dotado de certos atributos e equipamentos que o habilitam à produção discursiva. Aqui, confunde-se o escritor real com o letrado. Ocorre que o escritor real também se inscreve num discurso e não pode ser achado fora dele. Principalmente no caso dos árcades mineiros. A caracterização, pois, do letrado, do escritor real, implica ter em conta outros discursos, sobremodo o histórico, o sociológico, o memorialístico e o (auto)biográfico. Conquanto não deixem também de ser construídos por uma subjetividade, com base numa grade teórica e à luz de certos documentos, constituem-se em discursos de outra ordem; propõem-se a primazia do documental, a fidelidade ao real e certa objetividade.

\section{A formação letrada: biografias diversas, mesmas rotas e ritos}

Constitui-se num requisito indispensável ao poetar o acesso às práticas da leitura e da escrita - a formação letrada. Acesso viabilizado e em muito

1. Cf. FOUCAUL, 1988. p. 200-205.

2. C. FoucAULI, 1987. facilitado pela propriedade. Na sociedade mineira setecentista, era privilégio de poucos o acesso à formação letrada. Como um Cláudio Manuel da Costa, por exemplo, magistrado e homem de letras. Nascido em 1729, no distrito de Vargem do Itacolomi, do bispado de Mariana, era filho de pais abastados, que viviam da mineração e da lavoura. Até por volta dos quinze anos viveu em Vila Rica. Muito cedo ingressa no ritual de formação do letrado, pelas mãos de um tiopadre - Dr. Frei Francisco Vieira, que lhe ministra os primeiros estudos de Gramática e Latim. Naquele tempo era comum a formação inicial dos filhos das grandes famílias coloniais por um tio-padre ou padre-mestre, que facilitam o ingresso desses filhos afortunados na Universidade de Coimbra. Após estudar Filosofia no Colégio dos Jesuítas do Rio de Janeiro, Cláudio conquista a láurea de Mestre em Arte, em 1749. Parte para Coimbra e ingressa na Faculdade de Cânones, formando-se bacharel em Leis em 1753. Retorna a Vila Rica nesse mesmo ano, onde estabelece banca de advogado.

Na profissão liberal, alcança respeitabilidade e sucesso, realizando contratos advocatícios que the permitem bons rendimentos e vida financeira tranqüila, a exemplo do estabelecido com a Ordem de São Francisco, desde 1771 , pelo qual recebia anualmente 60 oitavas de ouro. Mas, tendo cumprido o percurso da formação letrada, estava Cláudio duplamente habilitado: para o ofício de poetar e para o desempenho de funções e cargos públicos. Na primeira habilitação, ele já dá os primeiros passos ainda estudante em Coimbra, quando arrisca suas primeiras composições, como o Munúsculo métrico. E enceta uma trajetória poética que culminará na publicação, em 1768 , de suas Obras poéticas. Quanto à segunda, inicia-a em 1754, exercendo por dois meses a função de almotacé em Mariana. Depois, ocupa os cargos de procurador substituto da Coroa e Fazenda, de juiz das Demarcaçōes de Sesmarias e de secretário do Governo da Capitania, este último em duas ocasiōes, nos governos de Luís Lobo da Silva e de D. José Luís de Meneses, Conde de Valadares. Afinal, é este o caminho: os filhos dos grandes das Minas Gerais, do patriarcado rural e da mineração, vão para Coimbra, estudam, formam-se bacharéis e voltam para ocupar altos cargos na administração régia. $\mathrm{E}$ as funções e cargos que Cláudio desempenha não apenas possibilitam ao magistrado um conhecimento mais efetivo de sua província natal, em viagens que empreende aos sertões, mas ainda fazem dele um íntimo do círculo do poder em Vila Rica. Intimidade que se mantém até seu envolvimento na frustrada conjuração de 1789, causando-lhe a morte na prisão em circunstâncias estranhas, em julho desse mesmo ano.

Em Gonzaga, a formação do letrado apresenta percurso e procedimentos bem semelhantes ao caso de Cláudio, não obstante as 
especificidades biográficas de cada um. Nascido em 1744, na cidade do Porto, era Tomás Antônio Gonzaga filho do Dr. João Bernardo Gonzaga, magistrado natural do Rio de Janeiro, com a portuense D. Tomásia Isabel Clarque Gonzaga. Sua mãe, perde-a Gonzaga antes de completar o primeiro ano de vida, e dele e de sua educação cuidam tios e tias maternos. Mas, em princípio de 1752, o menino já está no Brasil, para onde fora transferido o pai como ouvidor-geral de Pernambuco. Entre 1759 e 1761, estuda no Colégio dos Jesuítas na Bahia, ficando pronto para ingressar na Universidade. Já em 1762, está matriculado na Faculdade de Leis, em Coimbra, ocasião em que desfruta da amizade de um futuro companheiro de versos e de aventuras políticas, Alvarenga Peixoto.

Após formar-se, em 1768, Gonzaga põe-se a escrever a tese com que se habilitaria ao magistério na Universidade de Coimbra - o Tratado de Direito Natural. Dedicado ao Marquês de Pombal, este Tratado é dos primeiros frutos do magistrado Gonzaga, a se exercitar num campo discursivo - o jurídico - que legará profundas influências ao seu discurso poético. De sua pretensão ao magistério, no entanto, abdica-se ele, habilitando-se à magistratura. Entre 1779 e 1781, serve como juiz de fora em Beja. E já em 1782, encontra-se instalado em Minas Gerais, nomeado que fora ouvidor de Vila Rica. Logo inicia um convívio amistoso com o governador da Capitania, D. Rodrigo José de Menezes, e com seu secretário de governo, o poeta Cláudio Manuel da Costa. Deste se torna um grande amigo, nos versos e nas aspirações políticas.

No exercício de suas funções públicas em Vila Rica, Gonzaga vive um período de grandes e graves turbulências, a partir de 1783, em virtude dos sérios atritos com o novo governador, Luís da Cunha Menezes. Período e atritos dos quais as Cartas chilenas constituem uma consistente documentação. Tanto é que, em 1786, é nomeado desembargador da Relação da Bahia. Porém, em razão sobretudo, ao que parece, de seu namoro e noivado com Maria Dorotéia Joaquina de Seixas Brandão, permanece à frente da Ouvidoria até setembro de 1788. E, em Vila Rica, até 1789, quando, acusado de envolvimento na conspiração mineira, é preso e transferido para o Rio de Janeiro. Julgado, a pena que recebe é o desterro em Moçambique, para onde parte em 1792.

Intimamente associada ao exercício da magistratura, a poesia de Gonzaga começa com composições de caráter encomiástico. Além do Tratado, a Pombal parece ter dedicado também um soneto, em razão da reforma dos estudos universitários em Portugal, promovida pelo Marquês em 1772. Por ocasião da "viradeira", quando sobe ao trono D. Maria I, Gonzaga lhe dedica um poema de "congratulação". A sua obra poética mais significativa, contudo, é a que produzirá em Vila Rica e na prisão, como resultado de sua aventura amorosa e desventura política, concretizada nos poemas de Marília de Dirceu. Obra que tem uma vertente satírica nas Cartas chilenas, decorrente de suas desavenças com Cunha Meneses, o "Fanfarrão Minésio".

$\mathrm{Na}$ breve cronologia depreende-se a mesma rota e o mesmo rito da formação letrada. Para biografias diversas, um só destino e várias semelhanças. Semelhanças comuns, de resto, ao conjunto dos intelectuais, magistrados e poetas da Colônia. Com raríssimas exceções (um Caldas Barbosa, um Silva Alvarenga), são oriundos das famílias abastadas coloniais, fazem os estudos iniciais no Brasil, partem para a Metrópole a fim de realizar estudos superiores. E retornam bacharéis, normalmente com cargos e funções já assegurados na administração colonial. A formação letrada garante, em termos mais práticos, a ascensão ao estamento burocrático. E, embora comecem aqui, o acesso e o progresso nas práticas da leitura e da escrita só avançam e se consolidam e se legitimam noutro espaço, o espaço europeu. Mas à custa da introjeção de um olhar e de valores, sobremaneira os culturais, próprios dos centros colonizadores, das Metrópoles, e de um conseqüente recalcamento dos costumes e tradições locais, do ambiente de origem. $O$ que redunda freqüentemente em duplicidades afetivas, sentimentos de inferioridade e ambigüidades políticas por parte de nossos letrados. Deparam eles com o dilema de ser o outro, simulacros do colonizador, ou de não ser, caso busquem afirmar uma personalidade intelectual própria, com cores locais. Dilema que vivem e expressam, naquela época, à sua maneira.

Como um seu requisito mínimo e indispensável, a enunciação do discurso supõe um árduo e penoso processo de iniciação e formação no mundo das letras e das ciências. Só aqueles que a ele se submetem adquirem aptidão para as práticas da leitura e da escrita. Ora, no contexto da formação colonial da sociedade brasileira, calcada no modelo agrário-exportador, tais práticas constituem privilégio de muito poucos. No caso da sociedade mineira colonial do século XVIII, então, o domínio da leitura e particularmente da escrita é profundamente restrito e desigual. Trata-se de uma formação social marcada pela atividade extrativista, pela empresa mineradora, em que os interesses do Estado português e do Fisco, em primeiro plano, e os dos oligarcas e potentados locais sobrepujam todos os demais interesses. A educação, mesmo aquela visando a uma formaçāo técnica, está longe de ser uma prioridade. As escolas régias são poucas e insuficientes; os professores, mal remunerados. Criado em 1772, a cobrança do imposto do "subsídio literário" não viabiliza articular minimamente cobrança do imposto do "subs em todo o Reino. Com o uma rede escolar, predominando o desvio de recursos em todo o Reino. Como descenso da produção do ouro, acas escolas régias a desorganização geral e a improvisão 
administrativa: há redução de cadeiras e professores mudam de profissão. Desse modo, a grande maioria da população dessa sociedade mineradora está excluída do saber ler e escrever. Saber que embasa a construção do Estado moderno, cuja forma de governar e proferir a justiça se apóia na leitura e na escrita. Constituem boa parte dos excluídos os "desclassificados do ouro"'.

Mas, para os poucos que a elas acedem, significam as práticas da leitura e da escrita um intenso intercâmbio com o legado cultural greco-latino, o conhecimento dos clássicos modernos, quinhentistas e seiscentistas, e a assimilação de um já extenso acervo de autores e obras, incluindo-se poetas e juristas, teólogos e filósofos, pensadores e cientistas. $O$ que exige de nossos intelectuais e letrados uma memória tentacular, o esforço de enciclopedista. Por sinal, memorização e enciclopedismo, mais do que reflexão e tirocínio crítico, são traços característicos da atividade intelectual colonizada.

\section{A paixão da leitura}

Se não se pode falar de uma prática generalizada da leitura em Vila Rica, percebe-se no seu restrito grupo de letrados e intelectuais, contudo, uma entrega apaixonada ao exercício da leitura. Apesar da ausência no meio de imprensa e universidades, das dificuldades para aquisição de livros e do controle da circulação de informações e idéias, empenham-se alguns deles em formar bibliotecas pessoais, a exemplo de Cláudio, Gonzaga, Alvarenga Peixoto e o Cel. José de Resende Costa. A biblioteca mais fornida, contendo duzentas e setenta obras com aproximadamente oitocentos volumes, era a do Cônego Luís Vieira da Silva, professor do Seminário de Mariana e considerado por Eduardo Frieiro um ideólogo, um intelectual, "um clerc puro"".

Nessas livrarias pessoais destacam-se, primeiramente, os léxicos e dicionários; depois, as obras de Teologia, Direito, Filosofia e dos grandes autores da Antigüidade Clássica; e também os clássicos portugueses, franceses, espanhóis e italianos, juntamente com os tratados de oratória e poética. Não faltam ainda obras elementares de ciências e conhecimentos práticos: os tratados de História Natural, Física, Astronomia, Geometria, Geografia, e os manuais de Agricultura, Arte Militar e Medicina. Tais obras circulam entre os letrados, ansiosos de se

3. CI. SOUZA, 1986

4. FRIEIRO, 1981, p. 22. atualizarem no campo dos vários conhecimentos e da literatura. Prestam-se à fundamentação das sentenças dos magistrados, como o ouvidor Gonzaga; espicaçam a curiosidade científica de um pesquisador e naturalista como o Frei José Mariano da Conceição Veloso; e alimentam as ruminações de um poeta como Cláudio. Mas circulam essas obras dentro de um clima bastante favorável à troca de experiências de leituras. É o que se pode inferir desta incisiva interpelação de Critilo a Doroteu nas Cartas chilenas: "Já leste, Doroteu, a Dom Quixote?" (Carta 2a , 113). Do apego à leitura, à época, fornece ainda Critilo consistente notícia na Carta $3^{\mathrm{a}}$ :

$O$ velho Alcimidonte, certamente,

tem postas nos narizes as cangalhas

e, revolvendo os grandes, gordos livros, cos dedos inda sujos de tabaco,

ajunta ao mau processo muitas folhas

de vãs autoridades carregadas.

O nosso bom Dirceu talvez que esteja

com os pés escondidos no capacho,

metido no capote, a ler gostoso,

o seu Vergílio, o seu Camões e Tasso.

Na citação acima, faço dois destaques. De um lado, o emprego do adjetivo "gostoso" conota os ganhos secundários da leitura, a sua dimensão prazerosa, indiciando a recepção estética do texto. De outro, o uso reiterado do pronome possessivo em "o seu Vergílio, o seu Camões e Tasso" traduz tanto um convívio íntimo com os clássicos, quanto sugere a presença do livro como propriedade pessoal, guardado em casa, na biblioteca, como objeto de exibição e ostentação social.

Entre os escritores e letrados de Vila Rica notam-se, ainda, variados modos de leitura. Há a prática mais antiga do ler em voz alta, num grupo de amigos diletos ou de companheiros casuais. Isso pode ser inferido dos depoimentos dos inconfidentes nos Autos da devassa. No seu depoimento, Gonzaga confessa ter comparecido a uma reunião em casa de Freire de Andrade, pensando tratar-se tão somente de uma reunião literária, para leitura de "algumas estrofes" de Alvarenga Peixoto. Essas reuniões e encontros em casas de amigos

5. PROEHCA FILHO (Org.), 1996. p. 812. 
parecem comuns entre os nossos letrados. E é de se supor que, em tais ocasiões, propícias ao enlace da poesia com a política, eles liam não só produções poéticas de própria lavra, caso da aludida recitação do famoso Canto genetlíaco de Alvarenga Peixoto, referida no depoimento de Gonzaga, como também ouviam a leitura de passagens dos clássicos. Anteriores às academias oficiais, constituem essas reuniões exemplos da sociabilidade intelectual, desenvolvida em torno do livro, lido e discutido, emprestado e folheado. ${ }^{6}$

O hábito da leitura silenciosa no quarto ou na biblioteca, como incremento à reflexão pessoal, solitária, e estímulo à composição de sentidos versos, também parece bastante difundido no exíguo meio intelectual mineiro do Setecentos, conforme atesta Critilo no início de sua Carta $10^{\mathrm{a}}$. Bem como a leitura antes do deitar-se, ou a leitura na intimidade do casal, marido e mulher entregues ao texto. Na utopia doméstica de Dirceu, a propósito, a presença do livro e da leitura na vida do casal é significativamente registrada em três das oito estrofes da lira III ( $3^{2}$ Parte):

Verás em cima da espaçosa mesa

altos volumes de enredados feitos;

ver-me-ás folhear os grandes livros,

$$
\text { e decidir os pleitos. }
$$

Enquanto revolver os meus consultos,

tu me farás gostosa companhia,

lendo os fastos da sábia, mestra História,

e os cantos da poesia.

Lerás em alta voz, a imagem bela;

eu, vendo que lhe dás o justo apreço,

gostoso tornarei a ler de novo

o cansado processo.'

As estrofes transcritas suscitam algumas observações. Uma delas prende-se à reincidência da adjetivação "gostoso", já notada anteriormente. Nesse outro contexto, a agradável companhia da amada presenciando o ato da leitura

6. Cf. CHARTIER, 1991.

7. PROENÇA FILHO (Org.), 1996. p. 686. permite assinalar uma produtiva aliança entre texto e prazer, Eros e Saber, possibilitada pela privatização da leitura. Outra observação diz respeito à postura exibicionista do letrado, reveladora do prestígio social de seu ofício. Daí que exponha ostensivamente, no espaço textual poético, os instrumentos de seu saber e fazer: o processo e os pleitos, os "altos volumes" e "os grandes livros". O elemento mais expressivo da passagem, porém, reside na emergência da mulher como leitora, engrossando as fileiras do minguado público da poesia e do poeta na Colônia. Na privacidade do quarto, Marília lê o poema em voz alta e com expressiva entonação - "o justo apreço". E o seu pastor Dirceu lê, em contido erotismo, o corpo da voz que lê.

Bem se vê que os intelectuais e escritores de Vila Rica lêem de tudo. Devoram prazerosamente os textos alheios e os próprios, na tentativa de inserirse no espaço da tradição literária e cultural do Ocidente. E o fazem entretidos num laborioso empreendimento que, muitas vezes, já ensaia e realiza a reescrita do texto do outro, ensejando a escrita do texto próprio. Dentro de um jogo intertextual caracterizado por apropriações, traduções e, às vezes, singelas traições dos textos alheios.

\section{O doce sacrifício à escrita}

Não menos apaixonada parece ser a entrega desses magistrados e letrados das Minas Gerais do Setecentos à faina da escrita. Entrega de que resulta uma produção textual em que se cruzam diversas modalidades discursivas: 0 poético, o jurídico, o histórico, o retórico. Dessa oblação generosa de si à escrita, em rituais noturnos que se prolongam madrugada afora, dão testemunho eloqüente os seguintes versos do autor das Cartas chilenas:

Assim, assim, também, o teu Critilo

não cansa de escrever-te, enquanto encontra do tolo Fanfarrão, do indigno chefe, estranhas bandalhices que te conte.

Ah! sofre, amigo, que te gaste o tempo, pois conter-se não pode, bem que o queira, que a força da paixão assopra a chama, a chama ativa do picante gênio.'

8. Idem. p. 888. 
Mas o sacrifício compensa. E não só pelo prestígio social da palavra impressa. Do suor e sangue vertidos, convertidos em texto, nasce a figura de um heró: a do intelectual iluminista, determinado a denunciar os arbítrios e a tirania do governador. Figura que, em Gonzaga, se contrapõe à imagem do magistrado aristocrata e legalista, relativizando-a.

O apelo e o apreço à prática da escrita manifesta-se, ainda, quer na necessidade de cantar os heróis, imortalizando-os, quer no ímpeto para retratar a amada. No primeiro caso, tem-se a poesia panegírica: os poemas encomiásticos, produtos de ocasião (nascimento, morte, aniversário, elevação a cargos). Abundantes em Cláudio e Gonzaga, representam um discurso bastante convencional, codificado, que tem suas raízes na oração laudatória, forense e oficial. Presente na poesia medieval, a oração laudatória é marcada pelo discurso de gala, cujo alvo principal é o elogio.?

Quanto ao retrato da amada, como o de Marília, nele também predomina o elemento convencional. Revela, entretanto, um apelo à escrita de caráter impositivo e mesmo coletivo, como o demonstram estes versos de Gonzaga na lira 51: "Pega na lira sonora,/ pega, meu caro Glauceste;/ e ferindo as cordas de ouro,/mostra aos rústicos pastores/a formosura celeste/de Marília, meus amores". ${ }^{10}$ Ante a insistência de Dirceu, também Glauceste, nome árcade de Cáudio Manuel da Costa, se dispõe à prática da escrita, a fim de retratar a bela Marília.

Mas, em Cláudio, é sob a forma de uma compulsão à inscrição fecundada pelo trabalho da memória, que se exprime a entrega à escrita. Com efeito, sob o disfarce de pastores e pastoras, o escritor vê-se compelido a inscrever em troncos e penhas versos e cifras que expressam desventuras amorosas ou feitos heróicos. No soneto LIX, seja o caso, no rochedo há de se preservar a memória do infortúnio amoroso:

Com lágrimas meu peito enternecia

A dureza fatal deste rochedo,

E sobre ele uma tarde triste, e quedo

A causa do meu mal eu escrevia."

9. C. CURTIUS, 1979. cop. 8

10. PROEN(G FillHO (Org.), 1996. p. 624.

11. Idem. p. 77.
Uma vez considerada a enunciação do discurso poético em sua matriz histórica, já se pode concluir enfatizando: na Vila Rica setecentista, num distante espaço periférico, o agente de enunciação do texto poético são os homens de letras, devidamente familiarizados com as práticas da leitura e da escrita. A essas práticas só tem acesso uma minoria privilegiada, dotada de posses e cabedais que lhe asseguram certas vantagens. Normalmente ocupando funções e cargos públicos na administração colonial, esses letrados pertencem, ou se vinculam, a grupos sociais de prestígio: magistrados, militares, padres.

Já se percebe também que, conquanto seja movida pela paixão, por um infatigável ardor intelectual, não se pode afirmar que a poesia dos letrados de Vila Rica seja produto de personalidades eminentemente singulares e contenha traços individualizadores marcantes. É que esses escritores, mais preocupados em se incrustar no universal do que afirmar individualidades artísticas, mostramse bastante apegados aos cânones literários vigentes. Imbuídos de certa legalidade poética, dão vez e voz mais à tradição literária européia que a si mesmos e a elementos locais, conquanto também esses estejam presentes em sua poesia. Reescrevem-na, repetindo o já dito - pelos antigos e os clássicos modernos. Mas com algumas suplementações.

\section{ABSTRACT:}

From the point of view of an archeological analysis of the poetic discourse in the seventeenth century $M G$ and having as corpus the poetry of Cláudio Manuel da Costa and Tomás Antônio Gonzaga, this paper analyses the agent of its ennunciation, highlighting the ways of building up the man of letters and his attributes - the pratice of writing and reading - which entitles him to a legitimazed poetic discourse.

KEY WORDS:

Brazilian Literature, Colonial Poetry, Poet. 


\section{PAULO LEMINSKI E TORQUATO NETO: DOIS "KAMIQUASES"}

Fabrício Marques de Oliveira

\section{REFERËHCIAS BIBLIOGRÁFICAS} CARRATO, José Ferreira. Jgreja, lluminismo e escalos mineiros coloniais: notas sobre a cultura da decodêncio mineiro setecentista.

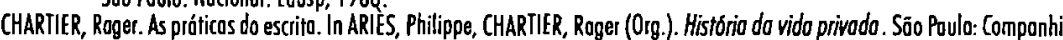
das Letros, 1991.v. 3: Da Renascenco ao Sécula das Luzes. p. 113-16

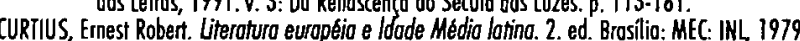

FOUCAULT, Michel. A orqueologio do sober. 3 . ed. Rio de Joneiro: Forense-Universitótrio, 1987.

"What is on outhor?". In LODGE, Dovid (Ed.). Modern crificism and theory. London, New York: Longman, 1988. p. 197 210.

FRIEIRO, Eduardo. O diabo no livrorio do conego : como era Gonzogo? e outros temos mineiros. 2. ed. rev. e aum. Bela Horizonte: Itatioio; Sóo Poulo: Edusp, 198

PROENÇA FiLHO, Domicio (Org.). A poesio dos inconfidentes: poesio completa de Clóudio Monuel da Costo, Tomós Anriônio Gonzogo Alvarenga Peixoto. Rio de Janeira: Nova Aguilar, 1996

SOUZA, Loura de Mello. Desclassificados da ouro : a pobreza mineiro no século XVIII. Rio de Janeiro: Graol, 1986.
RESUMO:

Este ensaio tem por objetivo a comparação entre dois poetas brasileiros contemporâneos, Paulo Leminski e Torquato Neto, no que concerne não somente ao Tropicalismo, mas também à concepção de poesia enquanto invenção. PALAVRASCHAVE:

Poesia Brasileira Contemporânea, Tropicalismo.

Concomitante ao seu surgimento na cena cultural e artística brasileira em fins dos anos 60, o tropicalismo trouxe consigo um redemoinho em cujo epicentro se desdobraram as mais diversas polêmicas. Estas, no entanto, eram guiadas numa só direção: o imperativo de falar do país. Nesse contexto, algumas perguntas aparecem: que é arcaico? Que é moderno? Qual música é erudita, e qual a popular? Deve-se trabalhar apenas com as raízes nacionais ou incorporar, além disso, as manifestações artísticas extrínsecas? A Tropicália coloca essas questões sob suspeita, relativizando-as e redimensionando-as. Ao lado delas, discute-se também a possibilidade de a canção ser, ao mesmo tempo, crítica e inserção no mercado. Isso porque, como assinala Celso Favaretto, "se por um lado, a atividade artística se realiza inevitavelmente segundo a ordem do mercado, por outro, não deixa de se afirmar como tentativa de transformação da 